\title{
Parent-child conversations in three urban middle-class contexts: Mothers and fathers reminisce with their daughters and sons in Costa Rica, Mexico, and Germany
}

\author{
Lisa Schröder ${ }^{1}$ \\ University Duisburg-Essen, Germany
}

\author{
Heidi Keller ${ }^{2}$ \\ Astrid Kleis ${ }^{3}$ \\ University of Osnabrück, Germany
}

\begin{abstract}
The present study investigated culture- and gender-differences in mother- and father-child reminiscing with 3-year old daughters and sons in urban middle-class families from Costa Rica, Mexico, and Germany. Families of the three contexts were overall similarly elaborative and children contributed a similar amount of memory elaborations. However, context specific use of different elaborative elements related to specific elaborative styles. Compared to the Latin American families, conversations in German families were least socially oriented. Across contexts, parents talked more about social aspects with daughters than with sons. Costa Rican mothers and fathers were equally elaborative, whereas German and Mexican mothers were more elaborative than fathers. We found similarities but also specificities in parent-child conversations about the past across these contexts with similar educational backgrounds.
\end{abstract}

Key words: Parent-child conversations, reminiscing, autobiographical memory, gender, culture, elaborations.

Resumen. El presente estudio investigó diferencias según cultura y género en las conversaciones sobre el pasado de niños y niñas de 3 años de edad con sus progenitores en contextos urbanos en Costa Rica, México y Alemania. En los tres contextos, el nivel de elaboración general de las conversaciones fue similar y los niños produjeron una cantidad similar de recuerdos. Sin embargo, se encontraron diferencias culturales en algunos aspectos de elaboración. En comparación con las familias latinoamericanas, las conversaciones de las familias alemanas estaban orientadas socialmente en menor medida. En todos los contextos, los progenitores hablaron más acerca de aspectos sociales con las hijas que con los hijos. Padres y madres costarricenses evidenciaron niveles de elaboración similares, mientras que las madres alemanas y mexicanas mostraron niveles de elaboración mayores que los padres. Nuestros hallazgos indican la presencia de similitudes y diferencias en las conversaciones sobre el pasado en familias con niveles educativos similares provenientes de distintos contextos culturales.

Palabras clave: conversaciones padre-hijo, reminiscencia, memoria autobiográfica, género, cultura, elaboraciones.

\footnotetext{
${ }^{1}$ Lisa Schröder, Faculty of Medicine, University Duisburg-Essen. E-mail: lisa.schroeder@uni-due.de

${ }^{2}$ Heidi Keller, University of Osnabrück. E-mail:

${ }^{3}$ Astrid Kleis, University of Osnabrück. E-mail:

Postal address: Department of Child and Adolescent Psychiatry, Psychosomatics and Psychotherapy, LVR-Klinikum Essen, Wickenburgstr. 21, 45147 Essen, Germany.
} 


\section{Introduction}

Cultural values and practices can be regarded as adaptive strategies that have evolved due to specific contextual demands (Rogoff, 2003). Contextual demands vary as a function of the ecosocial characteristics of a context. Depending on the respective ecosocial characteristics, specific cultural models can be defined (Keller, 2011; Keller \& Kärtner, 2013). In the present study we investigated three cultural contexts representing two cultural models: Middle-class families from Costa Rica and Mexico on the one hand and middle class families from Germany on the other.

All families had high formal education; however, varied in their household-types (extended in the Latin American and nuclear in the German context), the number of children, and the maternal age at the first child's birth.

According to the ecosocial conception of cultural models (Keller, 2011; Keller \& Kärtner, 2013) the Western, German middle class families can be regarded as representing the model of psychological autonomy, whereas the Latin American middle class families from Costa Rica and Mexico can be regarded as representing the model of communal psychological autonomy and relatedness. This means, that in both models the child's psychological autonomy ${ }^{4}$ is emphasized; however, in the Latin American contexts, it is also important that children develop strong family bonds and obligations. As previous studies demonstrated, these orientations are reflected in parental socialization goals, ethnotheories, and early mother-child interactions of Costa Rican and Mexican middle-class families compared to

\footnotetext{
${ }^{4}$ In contrast to "action autonomy" in non-Western, rural farming contexts, see Keller \& Otto, 2011.
}

German middle-class families (Kärtner, Borke, Maasmeier, Keller, \& Kleis, 2011; Keller, Borke, Yovsi, Lohaus, \& Jensen, 2005; Keller, Lamm, Abels et al., 2006). In the present study we looked at a social practice becoming particularly relevant for child development with the onset of language: Parent-child reminiscing during the preschool years. We investigated the intersection of culture and the individual characteristic of gender in mother-child and father-child past event conversations with daughters and sons. Revealing parent, gender, and culture specific mechanisms of reminiscing style and child development, is important to understand developmental pathways; in addition, it can be relevant to conceptualize sensitive intervention programs for families in order to advance children's development of language-, and literacy- skills (e.g., Reese, 1995; Reese, Leyva, Sparks, \& Grolnick, 2010).

\section{Mother-child reminiscing across cultures}

Talking about past events with children is a common practice in many different cultures (e.g., Eisenberg, 1985; Farrant \& Reese, 2000; Melzi, 2000; Mullen \& Yi, 1995; Wang, 2001) and influences children's understanding of themselves as a person in time, embedded in a cultural context (Conway \& Pleydell-Pearce, 2000). Early reminiscing is a social, languagebased practice that is particularly revealing to understand culture specific socialization practices and children's developing self-concepts. Cultural emphases are reflected in the way how parents involve children in these conversations on a structural level as well as in what they focus on of an event.

So far, cross-cultural research on early reminiscing has mainly focused on motherchild conversations. These studies revealed that 
mothers vary in their degree of structuring conversations more or less elaboratively (see Fivush \& Haden, 2003 for an overview). The elaborative style is characterized by questions (particularly open-ended Wh-questions) that embellish the conversation with information as well as regular positive feedback to child contributions (e.g., Fivush \& Fromhoff, 1988; Reese \& Fivush, 1993). This reminiscing style provides a scaffold for children to jointly reconstruct past events. In contrast, a low elaborative style is characterized by a high degree of repetitions (mothers repeating their own utterances) and more closed questions (yes/no questions). Children have fewer opportunities to contribute to the conversation.

The high elaborative style is common in Western middle-class families and has been related to the socialization goal of autonomy: children are encouraged to contribute their own opinions and memories to conversations and are thus treated as quasi-equal interlocutors (e.g., Wang, 2007). In contrast, mothers of Asian (mostly Chinese), African (Cameroonian), and Oceanian (New Zealand Māori) middleclass families have been reported as being less elaborative (e.g., Reese, Hayne, \& MacDonald, 2008; Schröder, Keller, Kärtner et al., 2013; Wang, 2001). The low elaborative style has been linked to their socialization goals relating to compliance with social roles: the child is following the lead of the mother and learns cultural messages in a teacher-novice format. This style is also and particularly pertinent in rural farming families with low formal education where children have to grow into their social roles as fast as possible (Schröder et al., 2013). Across and within cultures, maternal elaborative style is related to children's memory contributions concurrently and predictively (e.g., Farrant \& Reese, 2000;
Reese, Haden, \& Fivush, 1993; Schröder et al., 2013; Wang, 2006; 2007).

Also when looking at the content level, i.e. what mothers reminisce about, cultural differences emerge in congruence with the underlying socialization goals: mothers in Western middleclass families talk about the child, as the central character of an event and focus on the child's personal preferences and opinions, whereas in non-Western contexts, mothers talk more about other persons (i.e. social context) than the child and teach moral values and rules (Han, Leichtman, \& Wang, 1998; Schröder, Keller, Tõugu et al., 2011; Wang 2001; Wang, 2004; Wang, Leichtman, \& Davies, 2000).

\section{Reminiscing in Latin American families}

Latin American middle-class mothers (Peruvian: Melzi, Schick, \& Kennedy, 2004; Costa Rican: Schröder et al., 2013) and workingclass families from Central American countries living in the US (Melzi, 2000), are found to be similarly elaborative when reminiscing with their children compared to Western middle-class families (see different results for low-income Latino US families, Sparks, 2008). However, mothers have been found to vary in their way to use different elaborative elements(for a review of reminiscing in Anglo middle-class families and Latino families see Carmiol \& Sparks, in press). Melzi and colleagues (Melzi, 2000; Melzi et al., 2004) have revealed that mothers with Latin American background, structure conversations with many open questions and let the child take the narrator role, with mothers functioning as participators or elicitors. In contrast, EuroAmerican mothers ask less open -but more closed- questions, and in that way contribute also information of their own memories, thus, serving as conarrators or constructors. On the 
content level, conversations of Latin American families -similar to Asian families- focus on social aspects of events (i.e. are family-centered; Cristofaro \& Tamis-Lemonda, 2008) and talk about emotions more often, compared to EuroAmerican mothers (Eisenberg, 1999).

\section{Differences between mothers and fathers}

Mothers are typically studied in socialization research since they are considered to be the primary and most important caregivers. However, fathers in middle-class families are regarded as more and more important for child development in general (e.g., Lamb \& TamisLemonda 2004; Lamm \& Keller, 2012) and child language development specifically (e.g., Pancsofar \& Vernon-Feagans, 2006; Tamis-LeMonda, Shannon, Cabrera, \& Lamb, 2004). Thus, in the present study we looked at both motherchild and father-child reminiscing. Studies with fathers in the context of reminiscing are rare, especially from a cross-cultural perspective. So far, the findings comparing mothers and fathers are heterogeneous for both dimensions: how parents structure conversations and what they talk about.

The structure of mother-and father-child reminiscing

For the conversational structure of parents, some studies with Euro-American middleclass families find fathers and mothers to be equally elaborative (Reese \& Fivush, 1993; Reese, Haden, \& Fivush, 1996). Other studies with preschoolers but also older children, find mothers to be more elaborative than fathers (e.g., Zaman \& Fivush, 2013). With respect to children's gender, some studies find mothers equally elaborative with boys and girls within different cultures (e.g., Fivush \& Wang, 2005; Melzi, 2000; Melzi et al., 2011; Schröder et al., 2013). Yet in other studies with Euro-American middle-class families, mothers and fathers were found to be more elaborative with daughters than with sons (Fivush, Berlin, McDermottSales, Mennuti-Washburn, \& Cassidy, 2003; Reese \& Fivush, 1993; Reese et al., 1996). Thus, findings vary with respect to similarities and differences of mothers and fathers in structuring conversations with daughters or sons.

The content of mother-and father-child reminiscing

On the content level, parental differences have especially been revealed with respect to talk about emotions and social aspects of events. Mothers in Euro-American middle-class families have been found to refer to emotions more often than fathers do (Fivush, Brotman, Buckner, \& Goodman, 2000), other studies did not find such differences (Adams, Kuebli, Boyle, \& Fivush, 1995; Kuebli \& Fivsuh, 1992). Regarding children's gender, studies revealed mothers referring more often, to emotional as well social aspects of events with their daughters than with their sons (e.g., Buckner \& Fivush, 2000; Fivush et al., 2003; see Fivush \& Buckner, 2003 for a review). Also Mexican mothers were found to talk more about emotions with daughters than sons (Eisenberg, 1999) and Latin American parents living in the US talked more about socially oriented activities with daughters and more about action-based events with sons (Cristofaro \& Tamis-Lemonda, 2008). Peruvian mothers, however, talked more about emotional aspects with sons than with daughters (Melzi \& Fernandez, 2004). Thus, the most robust result may be a more social oriented focus during reminiscing with daughters than with sons.

\section{The present study and hypotheses}

In the present study we aim to investigate the structure and the content of parent-child pastevent conversations in three cultural middle- 
class contexts representing two cultural models. Based on previous studies with similar middleclass contexts, we formulated several hypotheses:

How: Elaborative structure

H1. Overall elaborativeness: We expected that contexts would not differ with respect to their overall elaborativeness.

H2. Use of different elaborative elements: We expected that Latin American parents would ask more open questions (elicitation/participator style) than the German parents, who in turn were expected to ask more closed questions or to make statements similar to Euro-American middle-class families (conarrator/constructor style).

H3. Child memory contributions: We expected that children would contribute a similar amount of memory elaborations across contexts.

\section{What: Content}

H4. Social orientation: We expected that conversations of the Latin American parentchild dyads would have a greater focus on socialthan nonsocial aspects of an event compared to the German context. Furthermore, we hypothesized that parents across contexts would talk more about social aspects of events with daughters than with sons.

With respect to mothers' and fathers' elaborativeness with their daughters or sons, we had no explicit hypotheses due to the mixed findings of previous studies.

\section{Method}

\section{Participants}

Families from three different urban cultural contexts participated in this study: $n=19$ families from San José, the capital of Costa Rica; $n=$
14 families from Guanajuato, a city in Central Mexico; and $n=22$ families from Osnabrück, a city in Northern Germany. In some families it was not possible to assess conversations for both parents. Because of that, the final samples consisted of 18 mother- and father- child conversations from San José, Costa Rica (28\% girls); 12 mother- and father- child conversations from Guanajuato, Mexico (42\% girls); and18 mother- and father- child conversations from Osnabrück, Germany (56\% girls). Due to withdrawing consent, unavailability, or technical problems, conversations were not available of one father of the Costa Rican context, one father of the Mexican context, and three fathers and one mother of the German context. Children were 36 months on average (ranging from 34 to 37 months). The distribution of children's gender did not differ significantly across contexts, $\chi^{2}(2, N=48)=2.86, p=.24$. However, within contexts there were more boys in the Costa Rican (13 of 18 children) and Mexican ( 7 of 12 children) contexts, and more girls in the German context (10 of 18 children).

Families from all three contexts held a high formal education and accordingly, did not differ in their years of formal schooling for mothers or fathers. All parents had at least 10 years of formal education and thus, at least secondary school level ("secundaria", "mittlere Reife"). In the Costa Rican and Mexican contexts, household sizes were significantly bigger compared to the German families. Mothers of the German context were significantly older when they had their first child compared to mothers of the Costa Rican and the Mexican context. In the Costa Rican context $56 \%$ of children were firstborns, $36 \%$ of children were firstborns in the Mexican context, and all children of the German context were firstborns, $\chi^{2}(2, N=$ 
Table 1

Mean differences of sociodemographic information among samples

\begin{tabular}{lccccc}
\hline & $\begin{array}{c}\text { Osnabrück } \\
M(S D)\end{array}$ & $\begin{array}{c}\text { San José } \\
M(S D)\end{array}$ & $\begin{array}{c}\text { Guanajuato } \\
M(S D)\end{array}$ & $\begin{array}{c}F_{\text {-value }} \\
\left(\eta_{\mathrm{p}}{ }^{2}\right.\end{array}$ & $\begin{array}{c}\mathrm{df} \\
\text { (error, sample) }\end{array}$ \\
\hline Maternal years of formal education & 14.50 & 12.61 & 15.17 & 2.40, n.s. & $(45,2)$ \\
& $(3.75)$ & $(2.43)$ & $(4.13)$ & & \\
Paternal years of formal education & 14.39 & 15.35 & 15.64 & .71, n.s. & $(45,2)$ \\
& $(3.54)$ & $(3.10)$ & $(1.86)$ & & \\
Maternal age when having first child & $30.677_{\mathrm{a}}$ & $25.40 \mathrm{~b}$ & $26.33_{\mathrm{b}}$ & $6.54 * *(.23)$ & $(46,2)$ \\
& $(3.60)^{2}$ & $(4.24)$ & $(6.29)$ & & \\
Number of persons living in household & $3.56_{\mathrm{a}}$ & $4.44_{\mathrm{b}}$ & $4.75_{\mathrm{b}}$ & $4.79 *(.18)$ & $(47,2)$ \\
& $(0.92)$ & $(1.29)$ & $(1.14)$ & & \\
\hline
\end{tabular}

Note. Means of samples not sharing indexed letters differ significantly from each other.

$* p<.05, * * p<.01$

$49)=14.79, p<.01$. For means and statistical indices of the sociodemographic information see Table 1.

\section{Procedure}

Families were visited at home by female trained research assistants, either being native speakers or bilingual Spanish - German speakers. Mothers and fathers were asked to discuss two shared past events with their daughter or son each. In line with the procedure proposed by Reese and Fivush (1993), the research assistants asked parents to select events that had occurred within the last four weeks, and that parent and child had experienced together; these events should be specific and not routine events. Furthermore, events were supposed not to contain a story line, for example talking about the content of a book or film. Parents were asked to choose the place for this conversation and no time limit was set. Mother- or father- and child pairs were left alone in their place of choice during the conversations. Conversations with each parent took place within one week. The order of mothers or fathers having conversations was first counterbalanced. Conversations were audiotaped and subsequently transcribed verbatim.

\section{Coding}

The coding procedure for parental structuring of conversations during reminiscing was adopted from Reese and Fivush (1993).

Type of talk. Four different types of talk were differentiated: a) Event talk: all talk directly referring to the specific shared past-event in past tense; e.g., "What happened at the lake?"; b) Associative talk: all talk related to the event; e.g., general knowledge like "how is your cousin's name?", talk related to another past event or the future, e.g., "I want to go there again.", or the present; e.g.; "Where is the present you got now?"; c) Meta-talk: all talk about the situation itself; e.g., "I want to talk about our visit to grandma now." or about memory performance; e.g., "You can't remember?"; and d) Off-topic talk: all talk about aspects not related to the past event: e.g., "Sit down", "I want to go out now", "I am hungry". 
All types of talk were coded based on propositions (i.e. independent sentences) with the exception of off-topic talk that was coded per turn for parent and child. For each conversation the starting point was set when the parent asked the first specific question (or made a specific statement) about the event under discussion; thus, coding for a conversation always started with event talk. A conversation was deemed as finished when only meta-talk or off-topic talk continued. Thus, conversations always ended with event talk or associative talk. Only within event talk, specific codes were differentiated (e.g., different types of questions). Associative talk was not differentiated for different types (thus, associative talk was applied to questions, confirmations etc.).

Elaborative structure of event talk. Coding unit for the elaborative structure of event talk were independent sentences (i.e., propositions). This means that a structure code was applied for each independent clause (potentially including dependent clauses). For example both of the following sentences received one structure code: "Do you remember where we were yesterday?" "Do you remember what we did yesterday when we visited grandma and grandpa?"

The coding scheme within event talk (adopted from Reese \& Fivsuh, 1993) was exclusive and exhaustive. For the present study we only consider different elaborative elements as well as repetitions. Following, the here analyzed structure codes on the child's and parent's part are outlined:

A) Child memory elaborations: Child utterances that contained new information about the specific past event that had not been mentioned before by mother/father or child, were coded for child memory elaboration.
This code could also apply to just one word said by the child in case he/she did not build a whole sentence; e.g., M: "Who was there?" C: "Lena." In this case the child received one memory elaboration (if this person had not been mentioned before).

B) Parental elaborations: Elaborations -in contrast to repetitions- contain new information about the event under discussion that had not been mentioned before neither by the parent nor the child. Elaborations thus embellish the conversation with new aspects. Elaborations were coded for different elements:

a. Open questions: All open question elaborations, meaning Wh-questions, fell into this category; e.g.: M: "What did we do yesterday?"; F: "Where did you play yesterday?". Thus, children had to answer with a word or sentence instead of just "yes" or "no".

b. Closed questions: All embellished questions only demanding a "yes" or "no" answer of the child; e.g., F: "Did you swim yesterday?”; M: "Do you remember where we have been at the weekend?". The last example demonstrates that also questions containing a Wh-questionword, could be built as a closed question.

c. Statements: All embellished utterances not being a question but just a statement fell into this category; e.g., F: "Yesterday we went to the lake." Tag-questions also fell into this category, e.g., M: "You were swimming, weren't you?".

d. Confirmations: This code was applied to general positive feedback (evaluation), like "Yes", "Right", "That's correct" etc. Furthermore, repetitions of the child's answer also fell into this category; e.g.: C: "We 
played in the sand." M: "You were playing in the sand?". Mostly, repetitions of the child answers occur as closed questions. However, they have a different function compared to closed elaborative questions. Repeating the answer of an interlocutor, functions as a confirmation in that it demonstrates interest and active listening.

C) Parental repetitions: Parental utterances (statements or questions) that repeated information the mother or father had mentioned before; e.g.: F: "What did we do yesterday?" C: "Don't know" F: "Tell me what we did yesterday?". Thus, only repetitions of their own utterances -not the child's utterances- fell into this category. Also prompts not leading to a new aspect and containing no new information were coded for this category; e.g.: "Tell me about it.", "Say.", "Tell.".

For final analyses we collapsed all elaborative elements (a.-d.) and calculated a difference score by subtracting repetitions from the total elaboration score. Thus, we achieved an elaboration-repetition difference score as an overall indicator for elaborativeness. In addition, the different elaborative elements were considered separately in the following analyses.

Content. The content was coded independently of the structure for each subject-verb unit within event talk as well as associative talk. This means, in contrast to structure coding, more than one content code could be applied within an independent sentence, namely also for dependent sentences: "What did we do when the sun was starting to shine?" In this example two content codes were applied, one for "What did we do..." and one for "when the sun...". For the present study we only consider two content codes relevant to our study: social context and nonsocial context (similar to Buckner \& Fivush, 2000). We thought of these two codes as a strong indicator of social orientation.

A) Social context references: This code was applied for parental and child utterances referring to other persons but not the mother or the child as the subject of a sentence; e.g., M: "What was your cousin doing?" C: "Climbing." In this case, both mother and child would have received one code for social context each because the utterances are referring to another person as the subject (implied by the verb in the child's case) of the sentence.

B) Nonsocial context references: This code was applied for parental and child utterances not referring to persons but referring to objects, food, animals, numbers, physical appearances or attributes; e.g., F: "What color did the car have?" C: "Red." In this case also both, father and child would have received a code for nonsocial context.

Also here, we calculated a difference score for social context references minus nonsocial context references as the final measure. Thus, the higher the score, the more socially oriented -relative to nonsocial aspects- conversations were, with a score close to zero indicating an equal talk about social and nonsocial aspects.

Reliability. Two research assistants coded independently $20 \%$ of the transcripts from each context and inter-rater reliability was calculated. Transcripts of the Osnabrück context were coded in German; the Costa Rican and Mexican conversations were transcribed in Spanish first and then translated into English by bilingual research assistants. English transcripts were coded for these contexts as trained coders were fluent in German and English. Cohen's kappa 
was $\mathrm{k}=.89$ on average for structure coding and $\mathrm{k}=.87$ for content coding across contexts. Discrepancies were resolved by discussion. The same two research assistants coded the remaining transcripts.

\section{Results}

\section{Plan of Analyses}

In preliminary analyses we compared the number of events talked about by mothers and fathers across contexts and explored all variables for extreme outliers. Furthermore, we explored differences in the length of conversations and the type of talk referred to during reminiscing (event-, associative-, meta-, and off-topic-talk) in order to see whether the task of reminiscing was performed similarly across contexts.

For main analyses we conducted several repeated measure ANOVAs and MANOVAs with cultural context (3 levels) and children's gender (2 levels) as the between subject-factors, and parent (mother or father) as the withinsubject factor for all analyses. According to our hypotheses, we analyzed 1) the overall elaborativeness of parents (relative to repetitiveness) with the elaboration-repetition difference score as the dependent variable; 2) investigated differences in the parental use of different elements of the elaborative style (open questions, closed questions, statements, and confirmations); 3) differences in the amount of child memory elaborations and 4) the social orientation of conversations based on the social- nonsocial- context difference score. Finally, we calculated simple Pearson's correlations (two-tailed) across and among children's memory elaborations and the parental elaborativeness within each context.
Since violating sphericity is critical when conducting repeated measure analyses of variance with small sample sizes, degrees of freedom were corrected with the GreenhouseGeisser method in analyses with more than one within subject factor. Uncorrected $F$-values with corrected $p$-values and effect-sizes (partialeta squared: $\eta_{\mathrm{p}}{ }^{2}$ ) are reported. Significant main and interaction effects were followed by post-hoc $t$-tests with LSD (lowest significant difference), with a significance level of $p<.05$. Marginally significant effects with $p<.10$ were also followed up in case the effect size was at least medium (>.06; Cohen 1988).

\section{Preliminary Analyses}

Number of events. Preliminary results demonstrated that the number of events discussed by mothers varied from one to three events. The distribution of number of events differed significantly among contexts for mothers, $\chi^{2}(4, N=49)=10.58, p<.05$. In the Costa Rican context, $78 \%(n=14)$ of mothers discussed two events, $17 \%(n=3)$ one event, and one mother discussed three events. In the Mexican context, half of the mothers discussed one event with their children and the other half, two events. In the German context all mothers discussed two events with their children, except one mother talking about one event. The number of events discussed by fathers varied from one to four events; however, the distribution did not vary significantly among contexts.

In order to keep means comparable, we divided all codes by the number of discussed events, for mothers and fathers. Thus, all means analyzed and illustrated refer to means per event (see Reese \& Fivush, 1993).

Outliers. Next, we explored variables for extreme outliers; meaning for upper or lower 
outer fence values (defined by a coefficient $=3$ ). For all child and parental variables we found three extreme outliers in the German context (for maternal and paternal open questions elaborations, and paternal confirmations, all from different participants) and four extreme outliers in the Mexican context: three from the same father (his open question elaborations, statement elaborations and repetitions) and one for open question elaborations of a mother. All extreme outliers were upper fence values. Due to the small context sizes we did not want to exclude these participants. Instead, we decided to replace outliers by the next closest value as suggested by Tukey (1962) cited in Sachs (2003). In this way the direction of the outlier is still taken into account but not as an extreme.

Conversational length and type of talk. In order to compare the total length of coded conversations, and the different types of talk (event-, associative-, meta-, and off-topic- talk), we computed a repeated 3 (cultural context) $\mathrm{x}$ 2 (children's gender) measure MANOVA with parent and type of talk (including parental as well as child variables) as the within subject factors. A significant main effect was revealed for type of talk, $F(72,2)=253.40, p<.001, \eta_{\mathrm{p}}^{2}=.86$. Posthoc tests revealed across contexts, that parentchild event talk $(M=42.40, S D=2.10)$ was significantly higher than all other types of talk, whereas meta-talk referred to by parents and children, was significantly lower compared to all other types of talk. The amount of associative talk and off-topic talk did not differ significantly (associative: $M=8.09, S D=6.89$; meta-talk: $M=$ 2.62, $S D=2.56$; off-topic: $M=7.40, S D=7.72$ ). A marginally significant main effect for context revealed that conversations of the Mexican parent-child dyads were significantly longer than conversations of the German and Costa
Rican dyads, which did not differ from each other, $F(2,42)=3.07, p=.06, \eta_{p}^{2}=.13$. Longer conversations of the Mexican conversations were due to including significantly more associative-, meta-, and off- topic talk compared to the other two contexts but not event talk, which did not differ significantly among contexts (see Figures 1 and 2 for proportions and means).

A marginally significant main effect per parent demonstrated that there was a trend for mother-child conversations being overall longer than father-child conversations across contexts, $F(1,42)=3.24, p=.08, \eta_{\mathrm{p}}^{2}=.07$. A significant interaction effect for Type of Talk x Parent revealed that this effect was based on motherchild dyads talking significantly more about the specific past event (event talk: $M=47.87, S D=$ 17.69) than father-child dyads $(M=36.47, S D=$ 19.54), $F(78,8)=2.14, p<.05, \eta_{\mathrm{p}}{ }^{2}=.18$. Parentchild conversations did not differ significantly from each other with respect to associative talk (mother-child: $M=7.58, S D=7.61$; father-child: $M=8.61, S D=9.39)$, meta-talk (mother-child: $M=3.04, S D=3.69$; father-child: $M=2.20$, $S D=2.25$ ), or off-topic talk (mother-child: $M$ $=7.46, S D=10.78$; father-child: $M=7.35, S D$ $=9.52$ ).

Taken together, across the three contexts, mothers and fathers, and daughters and sons, the proportion of event talk accounted for the biggest part of conversations, indicating that families conformed to the task to reminisce about past events (see Figures 1 and 2).

\section{Main Analyses}

Conversational Structure. As outlined in the method part, all codes analyzed in the following were only applied within event talk, i.e. when mother- or father- child dyads were talking 


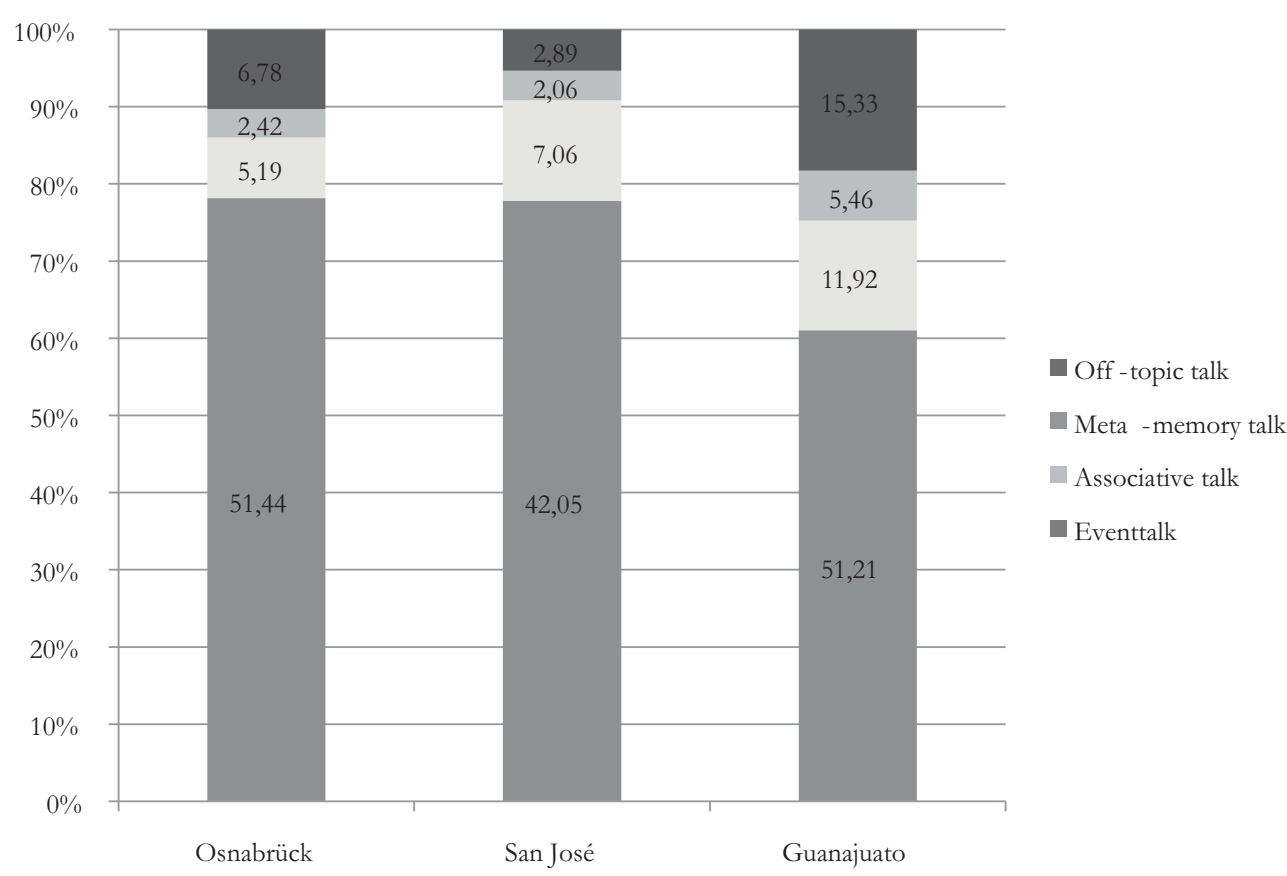

Figure 1. Percentages and frequencies (indicated on bars) of different type of talk during mother-child conversations within each context..

Note. Number on bars indicate mean frequencies per event.

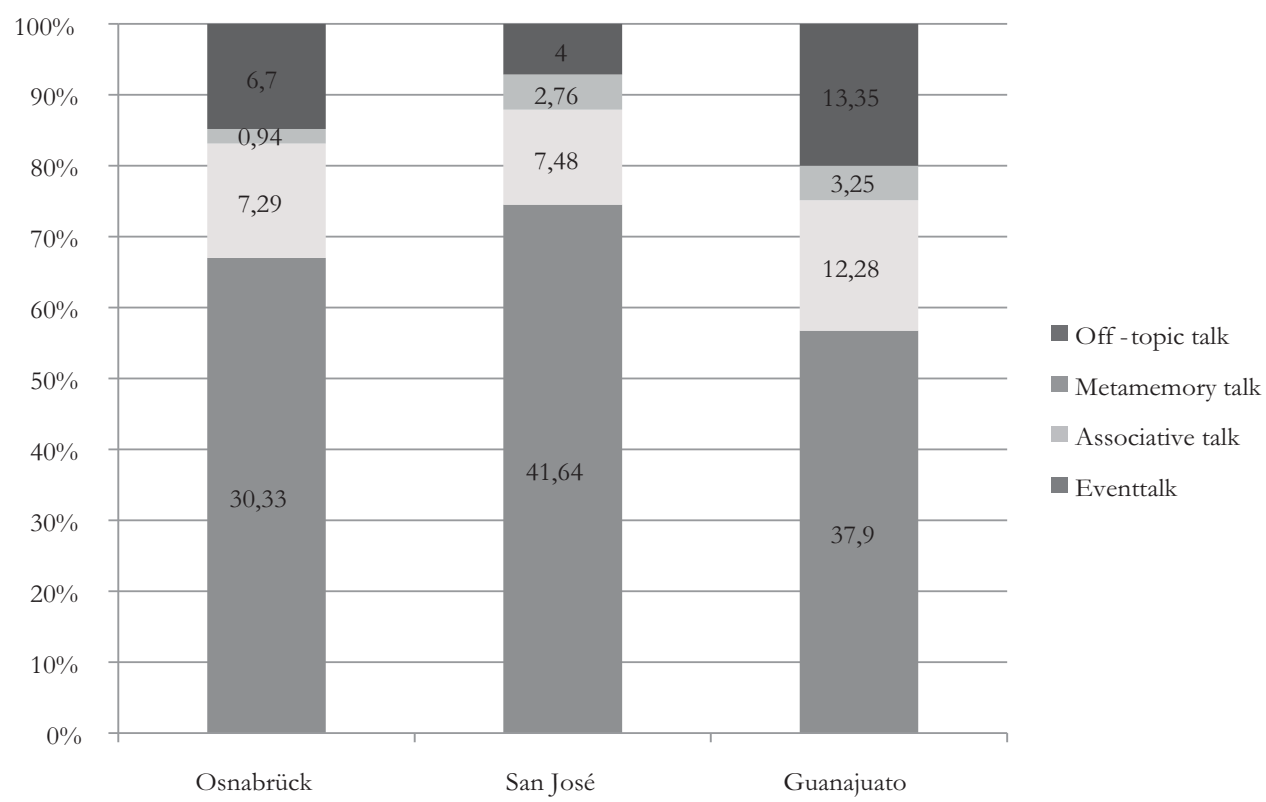

Figure 2. Percentages and frequencies (indicated on bars) of different type of talk during father-child conversations within each context.

Note. Number on bars indicate mean frequencies per event.

Actualidades en Psicología, 27(115), 2013, 49-73 
about the specific past event in past tense. The coding unit was proposition (i.e. independent sentences).

Overall elaborativeness. First, we investigated the overall elaborative structure by analyzing the difference score of total elaborations minus repetitions (see method part) by conducting a repeated 3 (cultural context) x 2 (children's gender) measure ANOVA with parent as the within subject factor and the elaborationrepetition difference score as the dependent variable. Across parents, the difference score did not differ among contexts. In line with our hypothesis, parents were thus, overall having similarly elaborative conversations with their children in the three cultural contexts. However, across contexts, mothers were overall more elaborative than fathers; with a main effect of parent, $F(1,42)=6.45, p<.05, \eta_{\mathrm{p}}^{2}=.13 \mathrm{~A}$ marginally significant interaction effect for Context x Parent, $F(2,42)=2.57, p=.09, \eta_{\mathrm{p}}{ }^{2}$ $=.11$ revealed that mothers' difference score in the German and Mexican contexts was higher than fathers' difference score, whereas in the Costa Rican context mothers and fathers were equally elaborative. Mothers of the German and Mexican context were adopting the most elaborative style; fathers of these contexts, the least elaborative style, and mothers and fathers of the Costa Rican context, both lay in-between (see Table 2 for all means). There was no effect for children's gender.

Elaborative elements. Next, we explored the use of different elaborative elements. For this purpose we calculated a repeated 3 (cultural context) $\mathrm{x}$ 2 (children's gender) measure ANOVA with parent (2) and structure (4) as the within subject factors. There was a main effect for parent with $F(1,42)=4.77, p<.05, \eta_{\mathrm{p}}^{2}=.10$ demonstrating that the use of elaborative elements was higher in mothers than in fathers across contexts. This indicates that the higher elaboration-repetition difference score in mothers was not due to fathers being more repetitive, but rather using less elaborative elements.

Furthermore, there was as expected a significant interaction effect for ElaborationElement x Context, $F(6,80)=2.62, p<.05$, $\eta_{\mathrm{p}}{ }^{2}=.11$. This effect was due to context specific use of different elaborative elements as followup t-tests demonstrated. Parents of both Latin American contexts used more open questions compared to the German context (Costa Rica: $t(34)=2.00, p=.05, d=.67$; Mexico: $t(28)$ $=2.14, p=.04, d=.80)$. Costa Rican and German parents confirmed child contributions to a similar degree and both more often than Mexican parents (Costa Rica: $t(28)=1.70, p=$ $.10, d=.63$; Germany: $t(28)=2.02, p=.05, d$ $=.75)$. Furthermore, parents of the German context made more elaborative statements than Costa Rican parents $t(34)=1.89, p=.07, d=$ .63 , whereas Mexican parents' use of statements did not differ from any of the two contexts and lay thus, in-between. Despite Mexican parent's use of closed questions was quite high (see Figure 3), contexts did not differ significantly in asking closed questions during conversations ( $p s$ $>$.10). Thus, compared to the other contexts, German parents made many elaborative statements and gave positive feedback, (i.e. confirmations) and asked less open elaborative questions. Costa Rican parents asked many open elaborative questions and regularly confirmed child contributions, but made few elaborative statements. Mexican parents also asked many open elaborative questions, made elaborative statements to a medium degree and were low in confirming child contributions (see Figure 3). 
In line with our hypothesis, these results indicate culture specific reminiscing styles that can be related to the constructor and elicitor styles (Melzi et al., 2011). There was no significant effect for gender, nor an interaction effect for parent, indicating that parents were similar in adopting these styles within contexts and did so similarly with girls and boys.

In order to substantiate our hypotheses, we also tested for significant differences within contexts. In line with previous research (Melzi et al., 2011), we tested for intra-cultural differences between parents' request of information (through open or closed elaborative questions) and parents provision of information (elaborative statements). In both the Costa Rican, $t(17)=7.71, p<.001, d=2.64$, and Mexican, $t(11)=5.70, p<.001, d=2.43$, contexts, parents asked significantly more elaborative questions compared to providing information through statements. In the German context, parents requests and provision of information did not differ significantly from each other, $t(17)=1.43$, $p>10$.

Child Memory Elaborations. In order to investigate children's contributions of memory elaborations during conversations, we calculated a repeated 3 (cultural context) x 2 (children's gender) measure ANOVA with parent as the within subject factor and child memory elaborations as the dependent variables.

As expected, there was no effect for cultural context. There was a marginally significant interaction effect for Context x Parent with $F(2$, 42) $=2.59, p=.09, \eta_{\mathrm{p}}^{2}=.11$. This interaction effect was due to children of the German context contributing significantly more memory elaborations when reminiscing with their mothers than with their fathers, $t(17)=2.89, p$ $<.05, d=1.37$; in the Costa Rican and Mexican

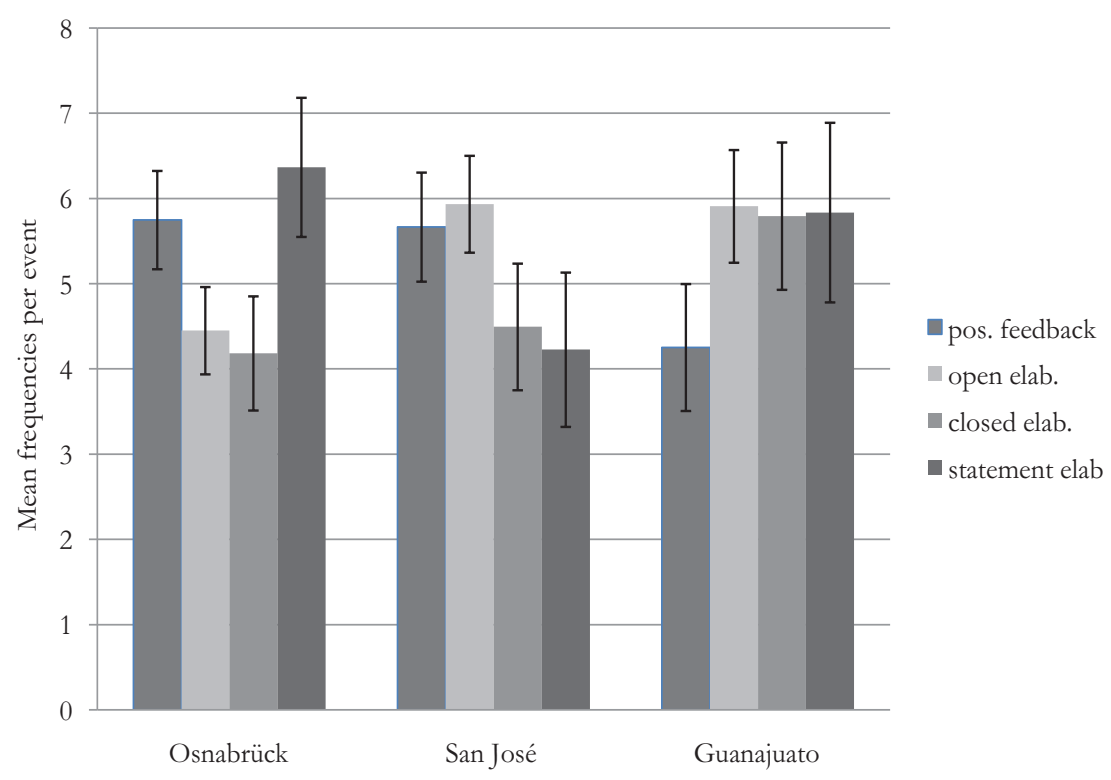

Figure 3.Mean values and standard-error for different elaborative elements as a function of cultural context.

Actualidades en Psicología, 27(115), 2013, 49-73 
Table 2

Means (Standard deviations) for conversational structure codes

\begin{tabular}{|c|c|c|c|c|c|c|c|c|c|}
\hline & \multicolumn{3}{|c|}{ Osnabrück, Germany } & \multicolumn{3}{|c|}{ San José, Costa Rica } & \multicolumn{3}{|c|}{ Guanajuato, Mexico } \\
\hline & Girls & Boys & Total & Girls & Boys & Total & Girls & Boys & Total \\
\hline \multicolumn{10}{|l|}{ Mother-child } \\
\hline $\begin{array}{l}\text { Elaboration-repetition } \\
\text { difference score }\end{array}$ & $\begin{array}{l}21.25 \\
(9.04)\end{array}$ & $\begin{array}{l}21.31 \\
(9.82)\end{array}$ & $\begin{array}{l}21.28 \\
(9.12)\end{array}$ & $\begin{array}{l}14.90 \\
(6.20)\end{array}$ & $\begin{array}{l}15.12 \\
(7.86)\end{array}$ & $\begin{array}{l}15.06 \\
(7.26)\end{array}$ & $\begin{array}{c}19.13 \\
(14.48)\end{array}$ & $\begin{array}{l}16.44 \\
(9.74)\end{array}$ & $\begin{array}{l}17.33 \\
(10.92)\end{array}$ \\
\hline Total Repetitions & $\begin{array}{c}3.30 \\
(1.95)\end{array}$ & $\begin{array}{l}4.25 \\
(2.41)\end{array}$ & $\begin{array}{c}3.72 \\
(2.15)\end{array}$ & $\begin{array}{l}6.90 \\
(5.16)\end{array}$ & $\begin{array}{c}4.45 \\
(4.41)\end{array}$ & $\begin{array}{c}5.13 \\
(4.61)\end{array}$ & $\begin{array}{c}4.38 \\
(3.94)\end{array}$ & $\begin{array}{c}8.31 \\
(5.06)\end{array}$ & $\begin{array}{c}7.00 \\
(4.93)\end{array}$ \\
\hline Confirmations & $\begin{array}{c}8.05 \\
(3.17)\end{array}$ & $\begin{array}{c}6.94 \\
(2.23)\end{array}$ & $\begin{array}{l}7.56 \\
(2.77)\end{array}$ & $\begin{array}{c}5.20 \\
(3.40)\end{array}$ & $\begin{array}{c}6.37 \\
(3.43)\end{array}$ & $\begin{array}{c}6.05 \\
(3.36)\end{array}$ & $\begin{array}{c}4.88 \\
(5.72)\end{array}$ & $\begin{array}{c}5.06 \\
(2.67)\end{array}$ & $\begin{array}{c}5.00 \\
(3.67)\end{array}$ \\
\hline Elab. Open Questions & $\begin{array}{c}5.50 \\
(1.87)\end{array}$ & $\begin{array}{c}5.31 \\
(2.27)\end{array}$ & $\begin{array}{c}5.42 \\
(1.99)\end{array}$ & $\begin{array}{c}7.00 \\
(2.15)\end{array}$ & $\begin{array}{c}6.19 \\
(3.79)\end{array}$ & $\begin{array}{c}6.42 \\
(3.37)\end{array}$ & $\begin{array}{c}5.63 \\
(4.23)\end{array}$ & $\begin{array}{c}7.56 \\
(1.82)\end{array}$ & $\begin{array}{c}6.92 \\
(2.81)\end{array}$ \\
\hline Elab. Closed Questions & $\begin{array}{c}3.70 \\
(3.28)\end{array}$ & $\begin{array}{c}4.50 \\
(3.02)\end{array}$ & $\begin{array}{c}4.06 \\
(3.10)\end{array}$ & $\begin{array}{c}5.40 \\
(3.73)\end{array}$ & $\begin{array}{c}3.71 \\
(2.25)\end{array}$ & $\begin{array}{c}4.18 \\
(2.73)\end{array}$ & $\begin{array}{c}4.63 \\
(3.09)\end{array}$ & $\begin{array}{c}7.31 \\
(3.28)\end{array}$ & $\begin{array}{c}6.42 \\
(3.35)\end{array}$ \\
\hline Elab. Statements & $\begin{array}{l}7.30 \\
(5.77)\end{array}$ & $\begin{array}{l}8.81 \\
(7.55)\end{array}$ & $\begin{array}{l}7.97 \\
(6.46)\end{array}$ & $\begin{array}{c}4.20 \\
(1.92)\end{array}$ & $\begin{array}{l}3.29 \\
(2.89)\end{array}$ & $\begin{array}{l}3.55 \\
(2.63)\end{array}$ & $\begin{array}{c}8.38 \\
(5.41)\end{array}$ & $\begin{array}{l}4.81 \\
(2.84)\end{array}$ & $\begin{array}{c}6.00 \\
(4.02)\end{array}$ \\
\hline $\begin{array}{l}\text { Child memory } \\
\text { elaborations }\end{array}$ & $\begin{array}{c}8.80 \\
(4.72)\end{array}$ & $\begin{array}{c}5.63 \\
(3.04)\end{array}$ & $\begin{array}{c}7.39 \\
(4.27)\end{array}$ & $\begin{array}{c}6.50 \\
(2.96)\end{array}$ & $\begin{array}{c}5.10 \\
(2.76)\end{array}$ & $\begin{array}{c}5.49 \\
(2.80)\end{array}$ & $\begin{array}{c}3.38 \\
(3.64)\end{array}$ & $\begin{array}{c}4.56 \\
(3.34)\end{array}$ & $\begin{array}{c}4.17 \\
(3.33)\end{array}$ \\
\hline \multicolumn{10}{|l|}{ Father-child } \\
\hline $\begin{array}{l}\text { Elaboration-repetition } \\
\text { difference score }\end{array}$ & $\begin{array}{l}14.12 \\
(8.09)\end{array}$ & $\begin{array}{c}12.56 \\
(11.72)\end{array}$ & $\begin{array}{l}13.43 \\
(9.58)\end{array}$ & $\begin{array}{l}18.00 \\
(2.76)\end{array}$ & $\begin{array}{l}13.37 \\
(8.48)\end{array}$ & $\begin{array}{l}14.66 \\
(7.56)\end{array}$ & $\begin{array}{c}15.21 \\
(11.65)\end{array}$ & $\begin{array}{c}8.90 \\
(5.74)\end{array}$ & $\begin{array}{l}11.00 \\
(8.22)\end{array}$ \\
\hline Total Repetitions & $\begin{array}{l}2.37 \\
(2.85)\end{array}$ & $\begin{array}{c}3.83 \\
(3.66)\end{array}$ & $\begin{array}{c}3.02 \\
(3.22)\end{array}$ & $\begin{array}{c}1.92 \\
(0.96)\end{array}$ & $\begin{array}{c}6.63 \\
(5.17)\end{array}$ & $\begin{array}{c}5.32 \\
(4.88)\end{array}$ & $\begin{array}{c}8.67 \\
(4.97)\end{array}$ & $\begin{array}{c}6.15 \\
(4.19)\end{array}$ & $\begin{array}{c}6.99 \\
(4.41)\end{array}$ \\
\hline Confirmations & $\begin{array}{l}4.15 \\
(3.05)\end{array}$ & $\begin{array}{l}3.85 \\
(3.02)\end{array}$ & $\begin{array}{l}4.02 \\
(2.95)\end{array}$ & $\begin{array}{l}5.67 \\
(2.26)\end{array}$ & $\begin{array}{c}5.42 \\
(4.67)\end{array}$ & $\begin{array}{c}5.49 \\
(4.08)\end{array}$ & $\begin{array}{c}4.00 \\
(4.97)\end{array}$ & $\begin{array}{c}3.07 \\
(1.88)\end{array}$ & $\begin{array}{l}3.38 \\
(3.93)\end{array}$ \\
\hline Elab. Open Questions & $\begin{array}{c}4.30 \\
(4.00)\end{array}$ & $\begin{array}{l}2.69 \\
(1.46)\end{array}$ & $\begin{array}{c}3.58 \\
(3.17)\end{array}$ & $\begin{array}{l}4.63 \\
(0.42)\end{array}$ & $\begin{array}{c}5.91 \\
(3.94)\end{array}$ & $\begin{array}{c}5.56 \\
(3.37)\end{array}$ & $\begin{array}{c}5.38 \\
(2.69)\end{array}$ & $\begin{array}{c}5.07 \\
(2.29)\end{array}$ & $\begin{array}{c}5.17 \\
(2.31)\end{array}$ \\
\hline Elab. Closed Questions & $\begin{array}{c}3.53 \\
(2.74)\end{array}$ & $\begin{array}{c}5.00 \\
(7.57)\end{array}$ & $\begin{array}{c}4.19 \\
(5.31)\end{array}$ & $\begin{array}{c}4.33 \\
(1.03)\end{array}$ & $\begin{array}{c}4.54 \\
(2.43)\end{array}$ & $\begin{array}{c}4.48 \\
(2.10)\end{array}$ & $\begin{array}{c}7.88 \\
(7.64)\end{array}$ & $\begin{array}{c}3.36 \\
(2.61)\end{array}$ & $\begin{array}{c}4.87 \\
(5.02)\end{array}$ \\
\hline Elab. Statements & $\begin{array}{l}4.50 \\
(3.65)\end{array}$ & $\begin{array}{l}4.85 \\
(5.06)\end{array}$ & $\begin{array}{c}4.66 \\
(4.20)\end{array}$ & $\begin{array}{c}5.28 \\
(2.53)\end{array}$ & $\begin{array}{l}4.13 \\
(3.53)\end{array}$ & $\begin{array}{c}4.45 \\
(3.25)\end{array}$ & $\begin{array}{c}6.63 \\
(1.60)\end{array}$ & $\begin{array}{c}3.53 \\
(1.82)\end{array}$ & $\begin{array}{l}4.56 \\
(2.27)\end{array}$ \\
\hline $\begin{array}{l}\text { Child memory } \\
\text { elaborations }\end{array}$ & $\begin{array}{r}4.17 \\
(3.30) \\
\end{array}$ & $\begin{array}{r}3.56 \\
(3.58) \\
\end{array}$ & $\begin{array}{r}3.90 \\
(3.34) \\
\end{array}$ & $\begin{array}{r}4.87 \\
(2.14) \\
\end{array}$ & $\begin{array}{r}5.82 \\
(5.62) \\
\end{array}$ & $\begin{array}{r}5.56 \\
(4.85) \\
\end{array}$ & $\begin{array}{r}5.38 \\
(6.37) \\
\end{array}$ & $\begin{array}{l}3.92 \\
(2.76)\end{array}$ & $\begin{array}{r}4.40 \\
(4.05) \\
\end{array}$ \\
\hline
\end{tabular}

Note. Some mean values include replaced outliers (see p. 58) 
contexts, children were contributing as many memory elaborations when reminiscing with their mothers as when reminiscing with their fathers. These results conform to the parental style differences across contexts and parents: mothers in the German context being overall more elaborative than fathers and mothers, and fathers in the Costa Rican context, being equally elaborative. However, results for the Mexican context fall out of this correspondence to the parental style. Also for this analysis, no gender effects were revealed.

Content of Conversations. As outlined in the method part, all codes analyzed in the following were applied within event talk, and associative talk. The coding unit was subject-verb constructions (i.e. independent and dependent sentences separately).

Social orientation. In order to investigate the social orientation of conversations, we calculated two repeated 3 (cultural context) $\mathrm{x}$ 2 (children's gender) measure ANOVAs with parent as the within subject factor and socialnonsocial- context difference score as the dependent variable for parents and children respectively. There were significant main effects for the analysis of parents' conversational social orientation, however, no significant main effects or interaction effects were revealed for children's social orientation in conversations (German context: $M=-2.09$, $S D=4.30$; Costa Rican context: $M=-1.36, S D=4.19$; Mexican context: $M=-2.01, S D=4.04)$.

For parents there were significant effects for cultural context, $F(2,42)=6.17, p<.01, \eta_{\mathrm{p}}{ }^{2}=$ .23 and for children's gender, $F 2,42)=5.10, p$ $<.05, \eta_{\mathrm{p}}{ }^{2}=.11$. No other effects were revealed. Post-hoc tests for cultural context demonstrated that relative to nonsocial contexts, parents of the German context $(M=-.79, S D=7.47)$ referred to social contexts significantly less often than parents of the Mexican context $(M=7.64$, $S D=9.60)$. The social orientation in parents of the Costa Rican context lay in-between by not differing from any of the two other contexts ( $M$ $=3.47 S D=8.21)$. Thus, our hypothesis was confirmed that conversations in the German families were least socially oriented. For children's gender, post-hoc tests revealed as expected that across contexts, the social orientation was significantly higher in conversations with girls $(M=7.80, S D=12.55)$ compared to boys $(M$ $=2.57, S D=12.66)$. However, the standard deviations indicate high intra-cultural and intragender variability.

\section{Correlations of parental and child variables}

All correlations were conducted within each context separately applying simple Pearson's correlations (two-tailed). Due to the small context sizes, more sophisticated statistics like regression analyses were statistically not feasible.

Because of high intercorrelations of the parental structure variables, we only conducted a correlation for overall elaborativeness of parents with child memory elaborations. Child elaborations were highly correlated with the elaboration-repetition difference score across contexts and parents (between $r s=.74$ and .87 , ps <.001), except for mother-child conversations in the Mexican context $(r=.18$, n.s.).

A significant relation for maternal and paternal elaborativeness was revealed within the Costa Rican context $(r=.51, p<.05)$, but not the $\operatorname{German}(r=.38$, n.s. $)$ and Mexican $(r=-.17$, n.s. $)$ contexts. Thus, in contrast to the German and Mexican families, children in the Costa Rican families, experienced a consistently (higher or 
lower) elaborative reminiscing style independent of who they talked to, mother or father.

Child memory elaborations contributed during mother-child and father-child conversations, were not significantly correlated in any context. However, the correlation coefficient was highest in the Costa Rican context $(r=.34, p=.17)$ compared to the German $(r=.11$, n.s. $)$ and Mexican $(r=.12$, n.s.) contexts.

\section{Discussion}

In the present study we investigated the elaborative structure and social orientation of mother-child and father-child conversations about shared past events in three urban middleclass contexts when children were three years of age. So far, cross-cultural studies have mainly focused on mother-child conversations; however, especially in urban middle-class contexts, the function of fathers as socialization agents has increased over the last decades (e.g., Lamb \& Tamis-Lemonda, 2004). We investigated contexts representing two different cultural models: the model of psychological autonomy in Western middle-class families from Osnabrück, Germany; and the model of communal psychological autonomy and relatedness: nonWestern middle-class families from San José, Costa Rica and Guanajuato, Mexico.

In line with our hypotheses, families of the three contexts did not vary in their overall elaborativeness and children contributed a similar amount of memory elaborations across contexts. As expected, parents differed in their use of specific elaborative elements that can be related to the elicitor and constructor styles. Furthermore, conversations in German families were least socially oriented compared to conversations of the Latin American families in line with the underlying cultural models. Results also confirmed the hypothesis that across contexts, conversations would be more socially oriented with girls than boys. Regarding differences between maternal and paternal reminiscing, results were heterogeneous across contexts. In the following, all results will be discussed in detail.

\section{Overall elaborativeness and different elaborative} elements

Overall, there were no cultural differences in conversational length or elaborativeness, in line with our hypotheses and previous studies investigating mother-child reminiscing in Latin American and Western Euro-American or European mothers with similar socioeconomic backgrounds (Melzi, 2000; Schröder, Keller, Kärtner et al., 2013; however, different to results of Melzi et al., 2011: Peruvian mothers having longer conversations than Euro American mothers). As expected, different elaborative elements were predominantly used in each cultural context, forming culture specific elaborative styles (as found for other cultural contexts; see Melzi, 2000; Schröder et al., 2011; Tõugu, Tulviste, Schröder, Keller, \& DeGeer, 2011). In the following, we will illustrate the differences among contexts with transcriptexcerpts ("M:" indicating maternal turns; "F:" indicating paternal turns; "C:" indicating children's turns; within conversations: " $\mathrm{xxx}$ " indicate ineligible words; “***” indicate a pause; (italic words) in brackets refer to nonverbal aspects or additional information).

Compared to the other contexts, the parental reminiscing style of the Costa Rican families was characterized by many open elaborative questions, regular confirmations and few elaborative statements. Following, the excerpt 
of a Costa Rican mother-child conversation is illustrated as an example:

M: Do you remember when we were bathing the doll? Closed elaborative question

C: yees, I remember.

M: And with... what did we put on the doll? Open elaborative question

C: My shampoo! (Laughs)

M: Your shampoo? Confirmation

And why did we use shampoo? Open elaborative question

C: Me full of shampoo made.

M: Full with shampoo? Confirmation

C: Yes.

M: And what did you do? Open elaborative question

What did you help me with? Open elaborative question

C: The doll was scared of the water.

M: The doll was scared of the water? Confirmation

And the doll was shaking herself, right? Statement elaboration

C: And made wet us.

M: Made us wet? Ah, yes. Confirmation (2)

(...) Associative talk (3 turns)

M: What happened? Open elaborative question

C: She just hurt herself.

M: But where did she hurt herself, where exactly? Open elaborative question

C: (no response)

M: Did she cry? Open elaborative question

C: No, the doll is brave.

In this example the conversational course is characterized by the mother asking an open elaborative question and then confirming the child's contribution by repeating the child's answer. The mother is giving positive feedback even when the child's response is not relating to what she had asked for. Thus, she follows what the child wants to talk about and does not -as in the German context- contribute her own thoughts or memories through elaborative statements. This style corresponds to the typical pattern of a high elaborative style (see Fivsuh et al., 2006 for a review). Also, other studies found Latino mothers to ask more open questions than EuroAmerican mothers (Melzi, 2000). Furthermore, parents were requesting more information than providing information when looking at intracultural differences. This style corresponds to the "elicitors style" (or high-eliciting; Haden et al., 2009) in Latino mothers when they distance themselves as the audience and let their children take the role of the narrator (Melzi, 2000; Melzi et al., 2011).

In the Mexican families, parents also provided many open elaborative questions but gave less positive feedback (confirmations), and were providing elaborative statements to a medium degree compared to the other two contexts. Following, the excerpt of a Mexican father-child conversation is illustrated as an example:

F: Do you remember when you were playing with them (meant are cousins)? Closed elaborative question

C: $\mathrm{Mmmm}$.

F: What did you play? Open elaborative question

C: $\mathrm{Mmmm}$.

F: To kick the ball. Elaborative statement

$\mathrm{C}: \mathrm{Mmm}$.

F: Not? Prompt (closed)

C: No.

F: What did you play? Repetition

C: With the scooter.

F: With the scooter? Confirmation 
C: Yes.

F: And who went on the scooter? Open elaborative question

C: Me.

F: And who else? Prompt (open)

C: Co Cechi.

F: Who from? From Ceci? Associative talk

C: (no response)

M: And the three little ones. Elaborative statement

C: Yes.

F: And where did you start from? Open elaborative question

C: $\operatorname{xxx}$ there.

F: On the platform. Elaborative statement

And did you have lots of fun with them? Closed elaborative statement

And what else were you playing? Open elaborative question

C: With the ball.

Like in the Costa Rican mother-child example, the father asks many elaborative questions. In contrast to the conversational course of the Costa Rican mother, he is though confirming the child's answer just one time. In the other two cases he goes on with asking another question without giving feedback to the child's contribution. Elaborative statements are made by the father as well. Looking at intra-cultural results, parents requested more information than they provided themselves like in the Costa Rican families. Thus, parents were also rather taking an elicitor role (Melzi et al., 2011). Styles still differed between the two Latin American contexts confirming heterogeneity of Spanishspeaking Latin American populations as claimed for other narrative contexts (Caspe \& Melzi, 2008).
Compared to the other contexts, parents in the German context made many elaborative statements and gave regularly positive feedback to their children's contributions, but they asked less open elaborative questions. Following, the excerpt of a German mother-child conversation is presented as an example:

M: On the playground, what was there? Open question elaboration

C: A amaziling slide!

M: A very amazing slide? Confirmation

C: A tunnel-slide!

M: A tunnel-slide? Confirmation

C: Yes.

M: Aha. How did you crawl inside? Open question elaboration

C: Yees. But I was, em, like em, like like backwards sliding.

M: You can already slide backwards? Associative talk (confirmation)

C: Yeeeeees.

M: (laughs) super! *** Associative talk (confirmation)

You know what I liked a lot? Closed elaborative question

C: What?

M: The frog. Statement elaboration

$\mathrm{C}:$ In there?

M: No, not not of this game; Statement elaboration but on the playground there was a huge frog. Statement elaboration

Do you remember that Dad was sitting next to it? Closed elaborative question

C: Yes. There also was, there is a frog inside.

M: Yes. *** Confirmation

And we saw Max and Moritz, huh? Statement elaboration 


\section{C: Aaahaaa.}

M: That was in the garden of fairy tales. Statement elaboration

In this example, the mother provides many elaborative statements and regularly confirms the child's contributions. In contrast to the examples of the Latin American contexts, she asks less open elaborative questions. This result -mothers making more elaborative statements and confirmations compared to other contextshas also been revealed for the German middleclass context of Berlin (Tõugu et al., 2011). Parents requested and provided information to a similar degree. This characteristic corresponds to the reminiscing pattern described by Melzi and colleagues (Melzi, 2000; Melzi et al., 2011) for Euro-American families: mothers being "conarrators" (constructors) i.e. they also provide information concerning their own knowledge to structure the conversation as they treat their children as equal interlocutors to foster their autonomy. In the investigation by Melzi (2000), however, mothers of the EuroAmerican families were high in asking closedended questions rather than making elaborative statements as in the present study ${ }^{5}$. Interestingly, when inspecting transcripts of the Osnabrück context, we noticed that children were also asking questions to their parents (as seen in the example above). Thus, parents making elaborative statements might be related to a bidirectional effect of the way children involve their parents in the conversation.

\footnotetext{
${ }^{5}$ It has to be kept in mind though, that the coding scheme slightly differed in that elaboration and different types of questions were coded separately in the study by Melzi (2000), and maternal requests in the study by Melzi et al. (2011) also contained memory prompts, whereas in the present study only elaborative utterances were coded for their type of being a question or statement.
}

Although the context specific styles have exemplarily been described and illustrated with individual excerpts, the respective style characteristics represent the mean differences for each element on a variable oriented level. The described patterns must not necessarily exist on an individual level, when determining each parent's pattern (being high or low in different elements; like in other studies, Haden at al., 2009; Schröder et al., 2013).

\section{Child Memory Contributions}

Overall, children's provision of memory elaborations did not differ among the three contexts despite parents used the elaborative elements to different degrees across contexts. This might be due to reciprocity effects between children's and parent's conversational behavior. For example, some children might contribute memory elaborations independently -without being asked- or even ask questions to their parents.

Children in the German families were contributing more memory elaboration when reminiscing with their mothers than with their fathers, whereas children in the Costa Rican and Mexican contexts provided an equal amount of memory elaborations within mother-child and father-child conversations. For the German and Costa Rican contexts, this corresponds to the differences in the parental reminiscing style: mothers being more elaborative than fathers in the German context, and mothers and fathers being equally elaborative in the Costa Rican context. Elaborativeness was highly correlated with children's memory contributions across parents within these contexts in line with multiple other studies across cultures (e.g., Farrant \& Reese, 2000; Reese \& Fivush, 1993; Wang, 2001; 2007). Only for the Mexican context, the result 
that children contributed an equal amount of elaborations is surprising since mothers were more elaborative than fathers were. Relating to this finding is the missing correlation of the maternal overall elaborativeness and children's memory in this context, which is surprising. Information about the frequency of motherchild reminiscing and information about situational motivation of children could possibly explain this finding.

\section{Differences between mothers and fathers}

Across cultural contexts, mother-child conversations were longer and focused more on the specific event under discussion (in relation to other types of talk) compared to fatherchild conversations, that were overall shorter and had a lower proportion of event talk; in line with studies on parental conversational behavior (Fivush et al., 2000; Pancsofar \& Vernon-Feagans, 2006). Furthermore, mothers were more elaborative than fathers (in line with Zaman \& Fivush, 2013); however, this was only true for German and Mexican families, whereas parents in the Costa Rican context were similarly elaborative (in line with Reese \& Fivush, 1993; Reese et al., 1996). Thus, overall our results confirm the heterogeneous findings of mothers being more elaborative than fathers in some contexts, and mothers and fathers being equally elaborative in others. In this respect, also the correlation patterns are important to consider.

A correspondence for mothers' and fathers' elaborativeness was only revealed within the Costa Rican context. Differences in the similarity and correspondence of paternal reminiscing style might be related to reminiscing traditions within families. It is possible that in the Costa Rican context, reminiscing might take place in a family setting rather than dyadic settings. In this way families may have established a "family reminiscing style" being similar in mothers and fathers, which might not be the case in families from the other cultural contexts. It is possible that in the Mexican families reminiscing takes place in one-to-one settings, yet neither mother nor father might be the most frequent conversational partners for reminiscing, but many other social partners (Eisenberg, 1985). However, these are speculations that would need to be studied empirically.

In general, it seems difficult to find a satisfactory explanation why studies differ in their findings about mothers and fathers elaborative contributions. An interesting aspect to explore could be the attitude concerning past event talk among parents. Regular reminiscing of parents with each other might also influence the parental consistency in their reminiscing style with their children. Various other task-, contextual, or individual factors might influence whether mothers and fathers do differ in their way to reminisce with their children (see Fivush \& Buckner, 2003 for a review).

Parental elaborative reminiscing did not differ overall as a function of children's gender in line with previous cross-cultural studies looking at the maternal reminiscing style only (e.g., Fivush \& Wang, 2005; Melzi, 2000; Schröder et al., 2013). On a structural level, an overall elaborative style with boys and girls might reflect the importance of educational achievement and academic success in both European and Latino families (e.g., Cristofaro \& Tamis-LeMonda, 2008; Keller, 2007), as an elaborative style is related to school relevant competencies like languageand literacy- development (e.g., Peterson, Jesso, \& McCabe, 1999; Reese, 1995; Reese, Leyva, Sparks, \& Grolnick, 2010; Sparks \& Reese, 
2013). In future studies it might be illuminating to consider also the influence of sibling's gender. Previous studies have revealed consistency across siblings in the maternal reminiscing style with children of the same gender (Haden, 1998). Investigating gender specificity and consistency across siblings in families with daughters and sons (ideally across cultures and parents) could be revealing.

\section{Content of conversations: Social orientation}

Cultural as well as gender differences, did though exist with respect to the content referred to during reminiscing. Conversations in the German families were least socially oriented and on average, parents referred more to nonsocial- than social aspects reflected in a negative difference score of social- to nonsocial references. In contrast, parents of the Mexican and Costa Rican contexts referred more often to social than nonsocial contexts reflected in their positive mean difference scores. The social orientation (relative to nonsocial aspects) in Mexican families was highest, and Costa Rican families' social orientation lay in-between. Thus, in line with the contexts' cultural models content reminisced about, reflected a higher relatedness orientation in the Latin American families compared to the German families. In line with previous studies (Buckner \& Fivush, 2000; Cristofaro \& Tamis-Lemonda, 2008; Fivush et al., 2003), conversations with girls were more socially oriented than conversations with boys: relative to nonsocial content, parents talked about social aspects more with girls than boys across contexts. This result also corresponds with women being conceived of as more relationally oriented than men, also reflected in women's autobiographical narratives as adults (Fivush \& Buckner, 2003 for a review). This orientation was, however, not yet found in what children referred to in conversations.

\section{Limitations}

A limitation of the present study is that mother- and father- child conversations were only assessed at one point in time. Thus, the generalization of these conversations might not be reliable for all families since the child's motivation in the specific situation, might also influence the conversational structure and content. It might be helpful in future studies to control for the overall motivation of children assessed by parental judgment (compared to other reminiscing situations). Furthermore, in contrast to studies cited here, the instructions for the present assessments did not ask parents to reminisce about specifically emotional events with their children as implemented in other studies (e.g., Fivush \& Wang, 2005; Melzi et al., 2004; Zaman \& Fivush, 2013). Thus, the overall emotional significance of the discussed events might vary among conversations and also influence the way of reminiscing.

\section{Conclusions}

Despite contexts having similar educational background and two contexts having a Latin American background, each cultural context was unique in the way parents and children talked about the past. This supports the importance to look at culture beyond the level of country as well as beyond ethnicity and educationaleconomic status (e.g., also family type and historical change; Keller \& Kärtner, 2013). In order to fully understand the socialization milieu of middle-class families, it is important to investigate parental behavior of both, mothers and fathers, but also other socialization agents that are important in the child's life. 
Reminiscing with children is an important practice and relevant to many different developmental areas such as language- and literacy development, but also social-emotional competencies (Reese et al., 2010; Van Bergen, Salmon, Dadds, \& Allen, 2010). Thus, findings in reminiscing are of great practical relevance as well. Cross-cultural studies like the present can contribute to conceptualize culture sensitive approaches adjusted to children growing up in families with migration history and thus, potentially different cultural backgrounds than predominant in the host society. Looking at gender differences might also have practical relevance; for example, encouraging parents to also talk with their sons about social-emotional aspects more intensively as it is related to emotion knowledge and might finally even prevent externalizing behaviors (Salmon, Dadds, Allen, \& Haws, 2009).

Reminiscing is a very important family interaction across cultures that influences many different developmental areas, but is also relevant to family bonds and the formation of childhood memories that, in turn, are fundamental for our identity.

\section{References}

Adams, S., Kuebli, J., Boyle, P., \& Fivush, R. (1995). Gender differences in parent-child conversations about past emotions: A longitudinal investigation. Sex Roles, 33, 309-323.

Buckner, J. P., \& Fivush, R. (2000). Gendered themes in family reminiscing. Memory, 8, 401-412.

Carmiol, A., \& Sparks, A. (in press). Narrative Development across Cultural Contexts: Finding the Pragmatic in Parent-Child Reminiscing. In D. Matthews (Ed.), Pragmatic Development in First Language Acquisition. Amsterdam: John Benjamins.

Caspe, M., \& Melzi, G. (2008). Spanish-speaking Latin American mother-child narrative discourse. In A.
McCabe, A.L. Bailey, \& G. Melzi (Eds.), Spanishlanguage narration and literacy: Culture, cognition, and emotion (pp. 6-33). New York: Cambridge University Press.

Cohen, J. (1988). Statistical power analysis for the behavioral sciences. Hillsdale, NJ: Lawrence Earlbaum Associates.

Conway, M. A., \& Pleydell-Pearce, C. W. (2000). The construction of autobiographical memories in the self-memory system. Psychological Review, 107, 261-288.

Cristofaro, T. N. \& Tamis-LeMonda, C. S. (2008). Lessons in mother-child and father-child personal narratives in Latino families. In A. McCabe, A.L. Bailey, \& G. Melzi (Eds.), Spanish-language narration and literacy: Culture, cognition, and emotion (pp. 5491). New York: Cambridge University Press.

Eisenberg, A. R. (1985). Learning to describe past experiences in conversation. Discourse Processes, 8 , 177-204.

Eisenberg, A. R. (1999). Emotion talk among Mexican American and Anglo American mothers and children from two social classes. Merrill-Palmer Quarterly, 45, 267-284.

Farrant, K., \& Reese, E. (2000). Maternal style and children's participation in reminiscing: Stepping stones in children's autobiographical memory development. Journal of Cognition and Development, 1, 193-225.

Fivush, R., Berlin, L. J., McDermott-Sales, J., MenutiWashburn, J., \& Cassidy, J. (2003). Functions of parent-child reminiscing about emotionally negative events. Memory, 11, 179-192.

Fivush, R., Brotman, M. A., Buckner, J. P., \& Goodman, S. H. (2000). Gender differences in parent-child emotion narratives. Sex Roles, 42, 233-253.

Fivush, R. \& Buckner, J. (2003). Constructing gender and identity through autobiographical narratives. In R. Fivush and C. Haden (Eds.) Autobiographical Memory and the construction of a Narrative Self: Developmental and Cultural Perspectives, (pp. 149-67). Hillsdale, NJ: Erlbaum. 
Fivush, R., \& Fromhoff, F. A. (1988). Style and structure in mother-child conversations about the past. Discourse Processes, 11, 337-355.

Fivush, R., \& Haden, C. A. (Eds.). (2003). Autobiographical memory and the construction of a narrative self: Developmental and cultural perspectives. Mahwah, NJ: Lawrence Erlbaum Associates.

Fivush, R., Haden, C. A.; \& Reese, E. (2006). Elaborating on elaborations: Role of maternal reminiscing style in cognitive and socioemotional development. Child Development, 77, 1568-1588.

Fivush, R., \& Wang, Q. (2005). Emotion Talk of Mother-Child Conversations of the Shared Past: The Effects of Culture, Gender, Event Valence. Journal of Cognition and Development, 6, 489-506.

Haden, C. A. (1998). Reminiscing with different children: Relating maternal stylistic consistency and sibling similarity in talk about the past. Developmental Psychology, 34, 99-114.

Haden, C. A., Ornstein, P. A., Rudek, D. J., \& Cameron, D. (2009). Reminiscing in the early years: Patterns of maternal elaborativeness and children's remembering. International Journal of Behavioral Development, 33, 118-130.

Han, J. J., Leichtman, M. D., \& Wang, Q. (1998). Autobiographical memory in Korean, Chinese, and American children. Developmental Psychology, 34, 701-713.

Kärtner, J., Borke, J., Maasmeier, K., Keller, H., \& Kleis, A. (2011). Socio-cultural influences on the development of self-recognition and selfregulation in Costa Rican and Mexican toddlers. Journal of Cognitive Education and Psychology, 10, 96112.

Keller, H. (2007). Cultures of infancy. Mahwah, NJ US: Lawrence Erlbaum Associates Publishers.

Keller, H. (2011). Culture and cognition: Developmental perspectives. Journal of Cognitive Education and Psychology, 10, 3-8.

Keller, H., Lamm, B., Abels, M., Yovsi, R., Borke, J., Jensen, H., et al. (2006). Cultural models, socialization goals, and parenting ethnotheories: A multicultural analysis. Journal of Cross-Cultural Psychology, 37, 155-172.
Keller, H. \& Kärtner, J. (2013). Development - The cultural solution of universal developmental tasks. In M. Gelfand, C.-Y. Chiu \& Y.-Y. Hong (Eds.), Advances in Culture and Psychology (Vol. 3), (pp. 63-116). Oxford University Press.

Keller, H. \& Otto, H. (2011). Different faces of autonomy. In: X. Chen \& K.H. Rubin (Eds.), Socioemotional Development in Cultural Context. New York: The Guilford Press.

Kuebli, J., \& Fivush, R. (1992). Gender differences in parent-child conversations about past emotions. Sex Roles, 12, 683-698.

Lamb, M. E. \& Tamis-Lemonda, C. S. (2004): The Role of the Father. An Introduction. In: Lamb, M. E. (Ed.): The Role of the Father in Child Development (4th ed.). Hoboken, NJ (John Wiley \& Sons, Inc.), S. $1-31$.

Lamm, B. \& Keller, H. (2012). Väter in verschiedenen Kulturen. In H. Walter \& A. Eickhorst (Eds.), Das Väterhandbuch: Theorie, Forschung, Praxis (pp 77-88). Gießen: Psychosozial-Verlag.

McCabe, A., Bailey, A. L., \& Melzi, G. (Eds.) (2008). Spanish-language narration and literacy: Culture, cognition, and emotion. New York: Cambridge University Press.

Melzi, G. (2000). Cultural variations in the construction of personal narratives: American and European American mothers' elicitation styles. Discourse Processes, 30, 153-177.

Melzi, G. \& Fernández, C. (2004). Talking about past emotions: conversations between Peruvian mothers and their preschool children. Sex Roles, 50, 641-657.

Melzi, G., Schick, A., \& Kennedy, J. (2011). Narrative Participation and Elaboration: Two Dimensions of Maternal Elicitation Style. Child Development, 82, 1282-1296.

Mullen, M. K., \& Yi, S. (1995). The cultural context of talk about the past: Implications for the development of autobiographical memory. Cognitive Development, 10, 407-419.

Pancsofar, N. \& Vernon-Feagans, L. (2006). Mother and father language input to young children: contributions to later language development. Journal of Applied Developmental Psychology, 27, 571-587. 
Peterson, C., Jesso, B., \& McCabe, A. (1999). Encouraging narratives in preschoolers: An intervention study. Journal of Child Language, 26, 49-67.

Reese, E., \& Fivush, R. (1993). Parental styles of talking about the past. Developmental Psychology, 29, 596-606.

Reese, E., Haden, C. A., \& Fivush, R. (1993). Mother-child conversations about the past: Relationships of style and memory over time. Cognitive Development, 8, 403-430.

Reese, E., Haden, C. A., \& Fivush, R. (1996). Mothers, father, daughters, sons: Gender differences in reminiscing. Research on Language and Social Interaction, 29, 27-56.

Reese, E., Hayne, H., \& MacDonald, S. (2008). Looking back to the future: Māori and Pakeha mother-child birth stories. Child Development, 79, 114-125.

Reese, E., Leyva, D., Sparks, A., \& Grolnick, W. (2010). Maternal elaborative reminiscing increases low-income children's narrative skills relative to dialogic reading. Early Education and Development, 21, 318-342.

Rogoff, B. (2003). The cultural nature of buman development. New York: Oxford University Press.

Sachs, L. (2003). Angewandte Statistik. Anwendung statistischer Methoden. (11th Edition). Berlin: Springer-Verlag.

Salmon, K., Dadds, M. R., Allen, J., Hawes, D. J. (2009). Can emotional language skills be taught during parent training for conduct problem children? Child Psychiatry and Human Development, 40, 485-498.

Schröder, L., Keller, H., Kärtner, J., Kleis, A., Abels, M., Yovsi, R. D., Chaudhary, N., Jensen, H., Papaligoura, Z. (2013). Early reminiscing in cultural context: Cultural models, maternal reminiscing styles, and children's memories. Journal of Cognition and Development, 14, 10-34.

Schröder, L., Keller, H., Tõugu, P., Tulviste, T., Lenk, M., Schwarzer, M., Rübeling, H., De Geer, B. (2011). Cultural expressions of preschoolers' emerging self: Narrative and iconic representations. Journal of Cognitive Education and Psychology, 10, 77-95.

Sparks, A. (2008). Latino mothers and their preschool children talk about the past: Implications for language and literacy. In A. McCabe, A.L. Bailey, \& G. Melzi (Eds.), Spanish-language narration and literacy: Culture, cognition, and emotion (pp. 273-295). New York: Cambridge University Press.

Sparks, A. \& Reese, E. (2013). From reminiscing to reading: Home contributions to children's developing language and literacy in low-income families. First Language, 33, 89-109.

Tamis-LeMonda, C. S., Shannon, J. D., Cabrera, N. J., \& Lamb, M. E. (2004). Fathers and mothers at play with their 2- and 3-year-olds: Contributions to language and cognitive development. Child Development, 75, 1806-1820.

Tõugu, P., Tulviste, T., Schröder, L., Keller, H., \& De Geer, B. (2011). Socialization of past event talk: Cultural differences in maternal elaborative reminiscing. Cognitive Development, 26, 142-154.

Van Bergen, P., Salmon, K., Dadds, M. K., \& Allen, J. (2009). The effect of mother training in emotionrich, elaborative reminiscing on children's shared recall and emotion knowledge. Journal of Cognition and Development, 10, 162-187.

Wang, Q. (2001). 'Did you have fun?' American and Chinese mother-child conversations about shared emotional experiences. Cognitive Development, 16, 693-715.

Wang, Q. (2004). The emergence of cultural selfconstructs: Autobiographical memory and selfdescription in European American and Chinese children. Developmental Psychology, 40, 3-15.

Wang, Q. (2006). Relations of maternal style and child self-concept to autobiographical memories in Chinese, Chinese immigrant, and European American 3-year-olds. Child Development, 77, 17941809.

Wang, Q. (2007). 'Remember when you got the big, big bulldozer?' mother-child reminiscing over time and across cultures. Social Cognition, 25, 455471. 
Wang, Q., \& Fivush, R. (2005). Mother-child conversations of emotionally salient events: Exploring the functions of emotional reminiscing in European American and Chinese families. Social Development, 14, 473-495.

Wang, Q., Leichtman, M. D., \& Davies, K. I. (2000). Sharing memories and telling stories: American and Chinese mothers and their 3-year-olds. Memory, 8, 159-178.

Zaman, W. \& Fivush, R. (2013) Gender differences in elaborative parent-child emotion and play narratives. Sex Roles, DOI: 10.1007/s11199-0130270-7.

Recibido: 21 de mayo de 2013

Aceptado: 02 de setiembre de 2013 